\title{
LA COMUNICACIÓN Y LA NATURALEZA EN LAS TEORÍAS PEDAGÓGICAS DE COMENIO, ROUSSEAU, PESTALOZZI, BUBER Y FREINET HACIA LA FUNDAMENTACIÓN DE UNA EDUCOMUNICACIÓN AMBIENTAL
}

“Más allá de la expresión y de la búsqueda del otro, la comunicación es el espíritu de los tiempos, la prensa, los medios, las canciones,

la publicidad, la moda, la música, la televisión, la radio (...)."

Wolton (2006)

"Obra de tal modo que tu acción no sea destructora de la posibilidad futura de vida"

Hans Jonas (1975)

\author{
SANDRA PATRICIA BASTO TORRADO \\ Docente investigadora del Centro de Estudios en Educación \\ Universidad Santo Tomás, Seccional Bucaramanga \\ Estudiante del Doctorado en Bioética, Universidad El Bosque \\ Magíster en Pedagogía, Universidad Industrial de Santander (UIS) \\ Especialista en Gerencia Social, Escuela Superior de Administración Pública (ESAP) \\ Comunicador social- periodista, Universidad Autónoma de Bucaramanga (UNAB) \\ sandrabasto@yahoo.com
}

\section{Cómo citar este artículo:}

Basto, S. (2011). La comunicación y la naturaleza en las teorías pedagógicas de Comenio, Rousseau, Pestalozzi, Buber y Freinet, hacia la fundamentación de una Edocomunicación ambiental. Espiral, Revista de Docencia e Investigación. 1, (1), 29 - 44

\section{Resumen}

Este artículo examina los conceptos de "Comunicación y Naturaleza" en los planteamientos pedagógicos de Comenio, Rousseau, Pestalozzi, Buber y Freinet. Asistimos a nuevos procesos comunicativos promovidos por la Sociedad de la Información y el Conocimiento. Entre tanto, la naturaleza se rebela para cobrar al hombre su desconsiderada acción sobre ella. Pese a lo signifcativo de estos dos términos en la supervivencia del planeta, la comunicación y la naturaleza continúan ignoradas por el campo educativo. Razón por la cual, este texto explora estos conceptos en las ideas de los grandes pedagogos con la pretensión de que la historia pedagógica se erija como un antecedente para un diseño edu-comunica- tivo ambiental potenciado por la mirada de algunos pedagogos contemporáneos de tal modo que responda a las necesidades ambientales surgidas en los últimos tiempos.

Palabras clave: comunicación, naturaleza, historia pedagógica, edu-comunicación ambiental.

\begin{abstract}
This article examines the concepts of "communication and nature" in the educational approaches of Comenius, Rousseau, Pestalozzi, Buber and Freinet. We are facing new communication processes promoted by the Society of Information and Knowledge.
\end{abstract}


Meanwhile, nature reveals to men its disappointment charging actions against them. Despite the signifcant of these two terms in the planet's survival, communication and nature remain ignored by the educational feld, which is why this text explores these concepts in the ideas of the great pedagogues with the claim that Pedagogical History should be raised as a precedent for environmental educational and communicative enhanced by the look of some contemporary educators, thereby meeting the environmental needs that have come out in recent years.

\section{Key Words}

Communication, Nature, Pedagogical History, environmental education and communicative.

\section{Introducción}

Signifcar "una educación por la comunicación" (Kaplún, 1985) no es tarea fácil, pues implica reconocer la comunicación como mediadora imprescindible para una educación que promueva la autonomía, la libertad, la igualdad, la crítica y la creación, entre otros. En este sentido Wolton (2006) expresa:

Para que la comunicación se imponga como un valor y una realidad ineludible en las relaciones humanas y sociales, se necesita una sociedad móvil, abierta, que mire hacia el cambio, privilegie la iniciativa(...)reconozca la singularidad y la igualdad de los sujetos, el derecho a expresarse, la libertad de opinión y fnalmente el pluralismo político (23).

Tal vez por ser la comunicación un campo disciplinar reciente aún no ha sido refexionado y accionado todo su potencial en la enseñanza-aprendizaje, ya que este proceso la ha deslegitimado, ignorándola o criticándola, reduciéndola sólo a técnicas, al desconocer toda la complejidad que encierra este concepto para la evolución de la educación, la cultura y la sociedad. Entre tanto, algunos teóricos latinoamericanos como Paulo Freire comprendieron la dinámica de una educación por la comunicación desde una perspectiva popular que si bien logró algunas transformaciones, suscitó un regreso a los viejos modelos tradicionales, dada la falta de legitimación de la comunicación desde las diferentes esferas de lo político y lo social.

Entre tanto, "lo ambiental" apenas comenzó a fnales del siglo pasado a fundarse como campo de estudio, más impulsado por la afectación del hombre sobre la naturaleza y la respuesta fatal de ella sobre el hombre, y no por una búsqueda auténtica donde el ser humano desee vivir en armonía y reciprocidad con el medio natural que le rodea. En este sentido, se manifestó Pautassi (1999) al asegurar: “(...) el hombre no sólo pertenece a la naturaleza en cuanto convive con ella, sino que es originalmente naturaleza, es producto inmanente de la evolución físicocósmica" (116).

Para Sagan (Fernández-Rañada, 2003) "los seres humanos son sólo los cuidadores de la tierra, puestos en ella con ese propósito y son responsables de ella, ahora $\mathrm{y}$ en el futuro, ante su propietario" (149).

Entre tanto, Paolo Lugari (2009) es quien hace referencia directa a la relación comunicación y naturaleza, al expresar:

"los seres humanos son sólo los cuidadores de la tierra, puestos en ella con ese propósito y son responsables de ella, ahora y en el futuro, ante su propietario"

¿Cómo cerrar la brecha entre la comunicación y la conciencia? (...) la comunicación que usamos ha incrementado nuestra capacidad de comprender lo esencial. La gente actúa no sólo cuando comprende el problema sino cuando lo siente. Hemos de sentir la piel de la tierra sobre la que nos movemos y somos, que ha sido afectada y necesita ser reconstruida. 
Por ello, este artículo explora los conceptos: "Comunicación y Naturaleza" desde los diversos horizontes propuestos por los grandes pensadores de la pedagogía moderna, de ahí que fueron seleccionados para este examen (Comenio, Rousseau, Pestalo-
"Comunicación implica diálogo, una forma de relación que pone a dos 0 más seres vivos en un proceso de interacción y de transformación continua". zzi, Buber y Freinet) dada la importancia de sus teorías en la educación. Por tanto, este texto pretende valorarlos a fn de determinar las referencias que los autores seleccionados implícita o explícitamente desarrollan. Esta introspección es de gran importancia para reconocer cómo la historia de la pedagogía puede contribuir a una fundamentación teórico-práctica de un diseño edu-comunicativo ambiental orientado a restablecer esa comunicación dialógica y transformadora del ser humano con su entorno, en una práctica pedagógica que realmente humanice y promueva la supervivencia armónica de la vida planetaria. Para Aparici (Ferrés, 2008) "Comunicación implica diálogo, una forma de relación que pone a dos o más seres vivos en un proceso de interacción y de transformación continua".

\section{La teoría Paido-centrista y Antropo- céntrica de Comenio}

Situémonos en Europa, siglos XVI y XVII, época en que surgió el movimiento Renacentista que signifcó un regreso a los clásicos griegos, desde una perspectiva cultural, científca y humana. Mirada que condujo a proponer una teoría Antropocentrista que planteó la idea de dominio del hombre como centro del planeta, fundamentada en la tradición judeo-cristiana, la ciencia moderna y el racionalismo instrumental. Al mismo tiempo, que avizoró una nueva concepción de hombre y su lugar en la sociedad. De ahí que surgieron importantes pensadores en los diversos campos del conocimiento. Para los fnes de este análisis, nos detendremos en la fgura de Juan Amós Comenio (1592-1670), sacerdote moravio, de orientación religiosa protestante, a quien se atribuyó el título de padre de la pedagogía al refexionar, por primera vez, sobre el rol del estudiante en el acto educativo. Este pensador propone en su teoría, al niño como eje del proceso pedagógico y considera importante activar todos sus sentidos a partir de la relación con su entorno, para que de esta forma ame el conocimiento. Al respecto Chateau (2005) expresa: "Para Comenio el hombre está rodeado por el mundo exterior, cuyo conocimiento adquiere, poco a poco, mediante los sentidos (...) así aprende a conocer y examinar las cosas en sí mismas, haciéndolo pensar por sí mismo" (119).

Sin duda Comenio le da una identidad al estudiante en el proceso formativo y sabe que llevarlo al aprendizaje dependerá de la manera en que se motiven sus sentidos. De este modo, se identifca un primer principio del proceso comunicativo, la identidad.

En efecto, una práctica pedagógica ambiental da comienzo a un auténtico proceso comunicativo cuando se reconoce al educando como una persona, capaz de pensar, expresarse y actuar por sí mismo, es decir, adquiere identidad.

Pero este sacerdote moravio fue más allá y trascendió la educación como proceso individual para proyectarla como un proceso social al plantear una educación para todos:

Se desea formar para la plenitud humana, no a un individuo, ni a pocos, ni siquiera a muchos, sino a todos y cada uno de los hombres, jóvenes y ancianos, ricos y pobres, nobles y plebeyos, varones o mujeres. Resumiendo: a cuantos hayan nacido 
hombres, para que todo el género humano, de cualquier edad, condición, sexo o nacionalidad, venga a ser educado" (Comenio, 2003: 48).

Siendo así, todo hombre o mujer puede ser educado. Este proceso contribuirá a desarrollar las posibilidades de expresión, de comunicación y, por ende, ampliará sus horizontes de saber. "no hay enten- De acuerdo con dimiento de la Prieto (1999) "no realidad, sin la posibilidad de la comunicación" hay entendimiento de la realidad, sin la posibilidad de la comunicación" (51). De hecho, la riqueza de la propuesta de Comenio, educación para todos, radica en el carácter democrático de la misma, lo que se constituye en otro principio fundamental para desarrollar una edu-comunicación ambiental, donde todos los individuos posean el mismo derecho a manifestarse, a dialogar, a comprenderse, a estar en "la red de seres humanos".

Comenio en su Didáctica Magna también planteó el acto pedagógico como un escenario donde el maestro se dirige a sus estudiantes siempre y cuando todos estén dispuestos a atender, es decir, a escuchar. "En esto han de tener los preceptores sumo cuidado, no hablarán sino cuando sean escuchados, nada enseñarán sin ser atendidos. Aquí viene lo que dijo Séneca: nada debe decirse a quien no está escuchando" (98).

En este postulado de Comenio se encuentra otro principio clave para desplegar una educomunicación ambiental: La escucha, la cual implica reconocer al otro, entrar en relación con el otro, considerar lo que el otro me manifesta, este es uno de los grandes desafíos de las sociedades modernas, escuchar, es decir, atender y procesar lo que mi interlocutor expresa.
Igualmente, para Comenio, las dudas, las preguntas y las respuestas deben ser puestas en común por los alumnos, es decir, en comunicación:

"no deben permitirse consultas privadas, sino que cada cual, ya por sí o ya por el Decurión (si este no ha sabido satisfacer las demandas) pregunte cuando necesite, pero públicamente, para que tanto las preguntas como las respuestas, sean útiles para todos" (99).

Se advierte un proceso de aprendizaje donde la puesta en común fomenta la escucha y la comunión de ideas, ejes esenciales de un proceso edu-comunicativo ambiental.

Despertar el interés y la motivación para cautivar al oyente, es también visible en la propuesta de Comenio, en efecto, le concede especial relevancia al uso de las imágenes al promover "una pedagogía de la imagen", donde la ilustración de textos será clave para que el niño adquiera el lenguaje, el "Orbis Pictus", es su gran obra audiovisual donde a cada palabra, corresponde una imagen. Sin duda, se encuentra en el pedagogo moravio un deseo por activar formas más motivantes para lograr el aprendizaje:

También reportará gran utilidad que el contenido de los libros se reproduzca en las paredes de la clase, ya los textos, ya los dibujos de imágenes o emblemas que continuamente impresionen los sentidos, la memoria, y el entendimiento de los discípulos. También Dios, nuestro Señor, ha llenado este inmenso teatro del mundo de pinturas, estatuas e imágenes, como señales vivas de su sabiduría, y quiere que nos instruyamos por medio de ellas (103).

De ahí que Comenio estableciera el uso de las imágenes en la educación, fundamento que sólo se incorporó en la práctica pedagógica de la primera modernidad, en los primeros años escolares, pero en los siguientes 
grados de la educación han sido totalmente subutilizadas por el maestro. Aunque la sociedad de la imagen invade hoy día todos los ámbitos individuales y colectivos, es aún exigua en las acciones pedagógicas de los diferentes niveles educativos, lo que sustrae al educando de formas de pensamiento y conocimiento simbólicas necesarias para comprender y participar de la sociedad de la información y el conocimiento. En este sentido, Gombrich expresa. “La imagen puede ser una herramienta de conocimiento porque sirve para ver el mundo mismo y para interpretarlo (...) crear una imagen es primero observar, elegir, aprender." (Citado por Joly, 2009: 68).

De hecho, integrar este lenguaje a un diseño educomunicativo ambiental será decisivo para una experiencia de aprendizaje signifcativa.

Así, Comenio en su Didáctica Magna promueve mediaciones, ya no centradas en el maestro, sino en el método, que a posteriori adquirirán gran sentido en el acto pedagógico al propiciar nuevos procesos comunicativos. En este aspecto Para Prieto (1999) la importancia de un método radica en que:

El método impulsa la comunicación y la interacción, va desde lo individual a lo interpersonal y a lo grupal, de lo cercano a lo lejano, ello signifca tomar al otro como punto de partida, a fn de construir desde él y con él a fn de permitirle su propia construcción de otras alternativas (30).

A posteriori, la didáctica se convertiría en un proceso comunicativo que hoy no solo acerca al niño de modo más sencillo al conocimiento, sino que establece una relación diferente entre el maestro y el alumno.

Respecto a la naturaleza, sobresale la visión Antropocentrica de Comenio (2003) al manifestar en su Didáctica Magna: “todos los que han nacido hombres lo fueron con el mismo fn principal, a saber, para que sean hombres; esto es, criaturas racionales, señores de las demás criaturas, imagen expresa de su Creador" (p. 30).

No obstante, propone que la "todos los que han nacido hombres lo fueron con el mismo fn principal, a saber, para que sean hombres; esto es, criaturas racionales, señores de las demás criaturas, imagen expresa de su Creador" capacidad expresiva del niño se potencie a partir de su relación consigo mismo, el entorno y los otros, pues el niño de Comenio se reafrma en su accionar con la naturaleza, la cual le brinda elementos para indagar, descubrir, expresarse y ser: "Si se quiere engendrar en los discípulos verdadero y exacto conocimiento de las cosas hay que procurar que la enseñanza toda sea por medio de la propia intuición y de la demostración sensual" (110).

En la teoría de Comenio se perfla una postura de superioridad del hombre sobre los demás seres, pero también concibe el desarrollo natural del niño en contacto permanente con el mundo que lo rodea. Esto es importante para una práctica pedagógica con transversalidad por lo ambiental, pues uno de sus fnes es: "mejorar las relaciones ecológicas, incluidas las del hombre con la naturaleza y las de los hombres entre sí (Novo, 2006: 396).

No obstante, algunos autores han dilucidado la obra de Comenio como la base del modelo pedagógico tradicional al concebir el método, la memoria y el orden, como proposiciones que se centran en la labor del maestro, para anular toda posibilidad de expresión del discípulo. Sin embargo, las diferentes teorías pedagógicas han sido de alguna forma llevadas a la práctica desde posturas positivistas que no interpretan, ni enrique- 
cen, ni reformulan lo asertivo, que encauzan con aquello que se difere. Además, no se puede olvidar que los distintos modelos se han erigido de acuerdo al tipo de sociedad y hombre que se ha pretendido proyectar en cada momento histórico. Y aunque Comenio presenta una visión antropocéntrica respecto a la relación del hombre con la naturaleza sus postulados abrieron caminos a la identidad del educando, así como a una educación por los sentidos. De ahí que estos postulados son signifcativos para fundamentar una educomunicación ambiental orientada a promover el hombre en comunicación consigo mismo y la otredad, esto es, en relación con todos los seres vivientes del planeta.

\section{La pedagogía naturalista de Rousseau y Pestalozzi}

Rousseau, (1712-1778) fue sin duda uno de los hombres más revolucionarios de su época y de mayor infuencia en el campo educativo. Su pensamiento surge en un período convulsionado por los aires de cambio impulsados por el movimiento de la Ilustración y la Revolución Francesa que, a la postre, dan fundamento a la sociedad moderna. Este flósofo de origen suizo no centró sus ideales en métodos, sino en la esencia del hombre, que se logra en el desarrollo de su propia naturaleza. En este sentido, el fn de la educación debe estar dirigido a orientar la naturaleza humana, fundamento básico para una educomunicación ambiental, en palabras de Novo (2006) "es necesario explorar el conocimiento menos conocido de todos: el espíritu humano que elabora el conocimiento" (409).

También, para este pedagogo, una educación por los sentidos dirigida por un preceptor va a constituirse en el eje para que el niño desarrolle su propia natura, en palabras de Chateau (2005) "para Rousseau (...) es en la infancia cuando el niño, utilizando los da- tos de sus sentidos logra construir a la vez las conductas humanas y la razón" (177). En efecto, la educación no debe arrebatarle al niño su propia naturaleza al pretender instruirlo en deberes adultos, sino, permitirle ser un menor, "la infancia tiene su propio método (...) tiene unas maneras de ver, pensar y sentir enteramente propias" (182).

Por tanto, esta Pedagogía de la libertad propuesta por Rousseau se orienta a responder a la necesidad pura del infante, donde es formado más por su propia espontaneidad, intuición y deseos, y no por las solas consideraciones del preceptor. Solo en ese sentido, podrá llegar a ser un hombre autónomo, libre, pensante y social. No obstante, en Emilio (2005) se percibe cierta ambigüedad de Rousseau respecto a la función del preceptor en la educación del menor al señalar:

"Emilio es huérfano, a pesar de tener padre y madre. Al hacerme cargo de todas sus obligaciones. Debe honrar a sus padres, pero a mí solamente debe obedecerme, esta es mi primera condición, o mejor dicho, la única".

Pero posteriormente, expresa:

"el más valioso de todos los bienes no es la autoridad, sino la libertad, por esto el único que actúa según su propia voluntad es el que para realizarla no tiene necesidad de la ayuda de nadie (...) esta es mi máxima fundamental: aplicarla a la infancia, y veremos como de ella se derivan todas las reglas de la educación" $(23,38)$.

Sin duda, se percibe su deseo de educar al niño conforme a los principios naturales de la infancia, pero al tiempo que lo hace libre, lo reduce a las reglas de su preceptor.

De igual forma, se encuentra en Rousseau una pedagogía que reconoce al niño como ser natural que se relaciona con su entorno de modo espontáneo, a través de los viajes, 
las observaciones y pocos libros. De acuerdo con Prieto (1996: 48) "la educación es un acto de libertad y no sólo como espacio para sentirse bien durante el proceso, sino como posibilidad de expresión, de comunicación y de crítica."

El infante para Rousseau (2005) debe ser inquieto, al indagar, descubrir, manipular y crear, desarrollar de manera libre sus propias formas de expresión:

"Lo que entra en el entendimiento humano viene por los sentidos, la primera razón del hombre es una razón sensitiva, la cual sirve de base a la razón intelectual, y de este modo, nuestros primeros maestros de flosofía, son nuestros pies, nuestras manos, nuestros ojos" (56).

Este contacto físico-emocional con nuestros órganos nos hará entender cómo somos, quiénes somos, nuestra naturaleza, y ante todo, el sentido de nuestra existencia en relación con el mundo que nos rodea, necesario para una formación ambiental, condición expuesta por las políticas ambientales colombianas:

"La piel más que un límite es una membrana de contacto, un sentido total que nos conecta con el medio y uno de los órganos a través de los cuales intercambiamos, energía e información (...) entre el individuo y el ambiente existe más bien lo que podríamos llamar "una zona de transición", "un campo de fuerza" cuyo espesor varía minuto a minuto de acuerdo a las circunstancias. A la pregunta sobre: ¿Dónde termino yo y dónde comienza mi ambiente? No existe una respuesta defnitiva (Ministerio de ambiente, vivienda y Desarrollo Territorial, 32, 33).
No obstante, el sujeto de la comunicación en Rousseau queda reducido, pues este niño que se construye a partir de sus sentidos y los impulsos de su propia naturaleza se debilita en su interacción, relación, contacto, capacidad de expresión con los otros seres, especialmente niños de su mismo edad, al ser sustraído de la escuela y formado en una mera relación con su preceptor, ya que es solo en la edad adulta donde está preparado para desenvolverse como ser social:

"Debe evitarse un contacto prematuro con la sociedad humana, así como con la estancia en ciudades que puedan incitar la disipación (...) introducid a un joven de 20 años en el mundo; bien educado, será dentro de un año más amable y más juicioso que el que se hubiera criado en él desde su infancia" $(107,111)$.

En este aspecto, el sentido de lo comunicativo surge en el pensador suizo también de una manera confusa, al concederle al niño la autonomía para indagar el mundo, para aprender, base fundamental de un proceso comunicativo. Pero por otro, lo limita en su construcción humana natural, "el ser social". Por ello, para Chateau (2005) la pedagogía naturalista de Rousseau, termina a posteriori en una pedagogía funcionalista que pliega "el ingenio, las humanidades y la comunicación social” (200). Pese a que en Rousseau hay una aspiración a la libertad individual, fundamental para la comunicación, la coarta en su dimensión social. En este sentido Wolton (2006) manifesta: "ser uno y libre no garantiza necesariamente el encuentro con el otro (...)" y agrega, es en "la intersubjetividad donde se halla la afrmación de sí y la relación con el otro" (28). De tal suerte que la noción de otredad imprescindible para una educomunicación ambiental, como bien lo expresa Leff (2006): 
(...) la racionalidad ambiental se abre así hacia el horizonte de la otredad (...) se forja en una relación de otredad en la que el encuentro entre seres diferentes se internaliza en la otredad del saber y del conocimiento, allí donde emerge la complejidad ambiental como un entramado de relaciones de alteridad (no sistematizables) entre lo real y lo simbólico, donde se reconfgura el ser y su identidad en la diversidad y la diferencia, y donde se abre a un más allá de lo pensable guiado por el deseo insaciable de saber y de justicia (70).

Al volver a Rousseau (2005) se encuentra un reconocimiento a la naturaleza como fundamento para el desarrollo de la curiosidad, la creatividad y la iniciativa del infante al afrmar:

"Motivad a nuestro alumno para que dedique tiempo y atención a los fenómenos de la naturaleza, y despertaréis su curiosidad, pero para alimentarla no os deis prisa a satisfacerla. Poned a su alcance las cuestiones y dejad que las resuelva. Que no sepa algo porque no se lo habéis dicho, sino porque lo haya comprendido él mismo; que invente la ciencia y que no la aprenda. Si por desventura, en su entendimiento sustituía la autoridad por la razón, no raciocinará más, y será el juguete de la opinión de otros (...) queréis enseñar geografía a este niño, y os apresuráis a presentarle globos, esferas y mapas; cuantos chismes. ¿Por qué en vez de esas representaciones no empezáis mostrándole el objeto mismo, a fn de que por lo menos sepa de qué se trata? (81).

Es evidente en este autor el imperativo de que el niño se relacione de modo direc- to con el ambiente que lo rodea, es otro principio relevante para una pedagogía ambiental, una educación por los sentidos que descubra, perciba, sienta, imagine y cree interacciones con el mundo (natural y superfcial). De ahí que, para Rousseau el primer libro signifcativo en el desarrollo sensitivo del niño es Robinson Crusoe, texto del que manifesta: "sólo en su isla sin la ayuda de sus semejantes y de los instrumentos (...) procurándose su alimento y su conservación” (90). En efecto, este niño sensible se realizará en el contacto con la naturaleza, razón por la cual sugiere que hasta los doce años sea preferiblemente criado en el campo donde el primer ofcio que debe aprender es la agricultura "siendo el más honroso, el más útil, y, por consiguiente, el más noble que puede ejercer" (96).

Asimismo, este autor manifesta en su Emilio:

En el corazón es donde está la vida del espectáculo de la naturaleza, y para verlo es indispensable sentirlo (...) si no ha recorrido aún por áridas llanuras, si sus pies no han quemado ardientes arenales, si jamás le colocó la ardiente reverberación de los roquedales encendidos por el sol. ¿Cómo queréis que el aire fresco de una bella madrugada sea capaz de recrearle? ¿Cómo pueden embriagar sus sentidos el aroma de las fores, el verdor de las plantas llenas de rocío y el suave y mullido caminar por el césped? (...) (82).

De este modo, se encuentra en este pedagogo suizo una explicitación distinta sobre la naturaleza al concebirla como parte esencial en la formación del niño, principio para signifcar una pedagogía ambiental. 


\section{Pestalozzi: "Soy obra de la naturaleza"}

A diferencia de Rousseau el suizo Enrique Pestalozzi, tal vez el educador más reconocido en el mundo, considerado "padre de la escuela pública moderna" es quien mejor concibe el ideal pedagógico desde una postura flantrópica, desarrollada en el ser social, siendo aquí donde vislumbra el sentido del hombre :

Tengo que actuar ahora en armonía con mis relaciones sociales, que yo mismo produje y traje al mundo; también en armonía conmigo mismo en la medida en que yo he cambiado por efecto de esas relaciones sociales. Yo produzco al mundo y el mundo se hace mundo por mí. Yo me considero obra del mundo y, al mismo tiempo, el mundo es obra de mi comportamiento. Soy una obra del mundo que es inseparable de mí, porque es mi obra (Citado por Böhm y Schiefelbein, 2004: 90).

Al mismo tiempo, este gran pedagogo llegó más lejos al llevar sus pensamientos a la práctica, pues logró desarrollar su propuesta educativa en su propia escuela popular, de tipo experimental, donde instruye a niños huérfanos y abandonados demostrando su gran altruismo y su vocación por la enseñanza. Para este maestro, el rol de la madre va a ser decisivo en la formación del niño, el amor, la dedicación, la comprensión y el respecto brindado por la progenitora son valores que reafrmarán la esencia del futuro hombre. Igualmente, el amor a sí mismo, el amor del maestro por su alumno y viceversa, serán los fundamentos de su educación integral. En términos de Chateau (2005) "es una pedagogía que forma el corazón, la cabeza y la mano".

Esta actitud flantrópica de Pestalozzi, permite identifcar una de las claves indiscutibles del proceso comunicativo, el respeto, de acuerdo con Prieto (1996): "un acto peda- gógico se funda en el respeto, la tolerancia y el reconocimiento de las especifcas características de todos y cada uno de los participantes" (46).

Entre tanto, Wolton (2006) advierte: "no hay comunicación sin respeto del otro, y no hay nada más difícil que reconocer al otro como un igual, sobre todo si no se le comprende" (p. 11).

Para Leonardo Boff (2009) el respeto es un principio básico en la relación del hombre consigo mismo y todos los seres de la tierra:

Respeto implica reconocer que cada ser tiene valor por sí mismo, por el mero hecho de existir y que, al existir, expresa algo del ser y de aquella Fuente originaria de energía y de virtualidades de la cual todos provenimos y a la cual todos retornamos (Vacío Cuántico).

De igual forma, en Pestalozzi es signifcativo el reconocimiento supremo que hace de la naturaleza, al exponer que somos obra de la naturaleza, pues, somos producto de ella y por tanto, parte imprescindible del devenir humano:

Como tal soy una obra de la necesidad; la misma esencia animal que después de milenios no puede cambiar ni un solo cabello de mi rostro o ninguna inclinación natural mía. Como obra de la naturaleza, ella me conduce sin reconocer las relaciones que yo mismo haya creado. Como si todavía estuviera en el inocente estado animal, ella me conduce con un mandato omnipotente al goce de los sentidos; tal como ella conduce al cóndor hacia la carroña, al cerdo al charco, al buey al pasto y a la abeja la lleva a las fores (...) como tal soy una gota de agua que se desliza, desde las cumbres de las montañas, en el medio de un arroyo. (Citado por Böhm y Schiefelbein, 2004: 90). 
Esto es especialmente relevante si se tiene en cuenta que aún no se vislumbraba una perspectiva antropocósmica que planteara al hombre como parte de la naturaleza y no como amo y señor de la misma, siendo este un fundamento para la educación ambiental, también señalado por Novo (2006): "una educación ambiental está orientada a una visión de los seres humanos como parte de la naturaleza en su conjunto, y la necesidad de una solidaridad interespecífca con el resto de los seres vivos no humanos" (406).

No obstante, para Pestalozzi este ser natural debe trascender en el ser social para posteriormente convertirse en un ser libre, autónomo, pensante, ético:

Como obra de la naturaleza me imagino el mundo como el animal que soy. Como obra de la sociedad me imagino el mundo como una criatura relacionada conmigo mismo y con otros seres humanos, como obra de mí mismo me imagino el mundo como algo independiente de mi egoísta naturaleza animal y de mis relaciones sociales; sólo lo imagino bajo el punto de vista de mi perfeccionamiento interior (91).

Ahora bien, el pensamiento de Pestalozzi difere del de Rousseau respecto a la familia y a la escuela, al considerar estas instituciones bases en la formación del niño, de acuerdo con Chateau (2005):

Para Pestalozzi la escuela le parece que constituye un momento esencial en la educación de la humanidad, puesto que ayuda al niño a enriquecer su experiencia de la vida personal y común, en un marco más amplio que el de la familia y más homogéneo que el de la ciudad. Sin embargo, cree que es la familia la única de todas esas potencias informadoras cuya bendición no es posible reemplazar por nada (...) (205).
Sin duda, el ser en comunicación se forma desde los primeros años en el seno de la familia, a través del lenguaje de los gestos y las señas que posteriormente desarrolla en la articulación de sus primeras palabras y es la motivación de la madre, clave en su capacidad expresiva y, por ende, comunicativa del menor.

Pestalozzi, también hizo de su método experimental un espacio de libertad y fraternidad, valores mediados por la naturaleza al situar su humilde escuela en el campo, allí donde los niños huérfanos tuviesen contacto con la naturaleza y una vida en común, es decir, en comunicación con todos los seres. A la vez, que se advierte en sus propuestas, el cuidado del cuerpo y el trabajo manual, ya fuese artístico, técnico o agrícola como ejes del proceso:

La gimnasia era objeto de una enseñanza metódica: se ejercitaba sucesivamente todos los miembros y todos los movimientos; se vigilaba también el modo de vestir de los alumnos en clase, los trabajos manuales ocupaban gran parte de la jornada del escolar de Yverdon: dibujando, cultivando, fabricando instrumentos (216).

En este mismo aspecto coincide Boff (2002) al proponer una ética del cuidado fundamentada en una espiritualidad dirigida a todos los seres para fomentar una pedagogía de la tierra:

Buscamos hoy ansiosamente una espiritualidad sencilla y sólida, basada 
en la percepción del misterio del universo y del ser humano, en la ética de la responsabilidad, de la solidaridad y de la compasión, centrada en el cuidado, en el valor intrínseco de cada cosa, en el trabajo bien hecho, en la honradez y en la transparencia de las intenciones (24).

En suma, Pestalozzi planteó una pedagogía popular centrada en el amor, el respeto, la naturaleza del ser, la experiencia, el contacto con la naturaleza, ideas muy signifcativas para promover un diseño educomunicativo ambiental, cuyo eje es el hombre en relación con la otredad (hombres-mujeresnaturaleza), para así alcanzar su propia esencia: "Mi instinto me hace una obra de la naturaleza, una visión animal. En cuanto obra de la sociedad soy una visión social. Y en cuanto obra de mí mismo, una visión ética de la verdad y el derecho" (Citado por Böhm y Schiefelbein, 2004: 91).

\section{La pedagogía de la comunicación de Buber y Freinet}

Es en el planteamiento del flósofo judeocristiano Martín Buber a principios del siglo $X X$, donde se encuentra una de las teorías de la comunicación más hermosas explicadas desde el plano metafísico Dioshombre, para luego trascenderla al ámbito humano, "Sí Dios se comunica dialogando con la gente, entonces, la comunicación entre los hombres, solo puede ser diálogo. Otra forma de comunicación negaría la enseñanza divina" como bien lo exponen (Böhm y Schiefelbein, 2004: 203) al referirse a la propuesta de Buber.

De este modo, esta pedagogía del diálogo desarrollada por este pensador vienés en su breve libro "Yo y tú" (1994) propone la relación del hombre con los otros seres, como un "tú" y no como un "ello", siendo la primera aquella donde el hombre entra en un dialéctica surgida en el respeto, la escucha, el diálogo, mientras en la segunda no hay reciprocidad, pues el "ello" implica un trato de mero objeto, en este sentido, expresa:

En cuanto a la frase "Yo veo el árbol", es pronunciada de tal modo que no expresa una relación entre el hombre -yo- y el árbol - tú-, sino que expresa la percepción del árbol como objeto por la conciencia humana, levanta una barrera entre el sujeto y el objeto. Entonces, se pronuncia la palabra primordial "Yo-ello", la palabra de la separación (...). Pero también puede ocurrir que por un acto de voluntad o por inspiración de la gracia, al considerar este árbol yo sea conducido a entrar en relación con él. Entonces, el árbol deja de ser un ello. Me ha captado la potencia de su exclusividad $(22,10)$.

En efecto, esta relación Yo y Tú se fundamenta para Buber en la correlación, la interlocución, la aceptación del otro y la comunicación, y es aquí donde es posible reafrmar la propia identidad, pero también la del otro, en este sentido manifesta: "el hombre se torna un Yo a través del Tú..." (26).

Buber no sólo hace referencia a un "tú" identifcándolo como ser humano, sino también a un "tú", como ser viviente. De ahí, su crítica al mundo actual por convertir al hombre, en un simple sujeto que sólo entra en relación con su entorno tratándolo como una cosa que manipula, y somete a su voluntad

“- ¿la vida colectiva de hombre moderno no está, acaso, sumergida necesariamente en el mundo del ello? (...). ¿La evolución de las formas del trabajo y de la propiedad moderna no han destruido casi todo rastro de vida recíproca, de relación plena de sentido?" (39).

Este pensamiento coincide con el planteamiento de Boff (2011) quien considera 


“-¿la vida colec-
tiva de hombre
moderno no está,
acaso, sumergida
necesariamente en
el mundo del ello?
(...). ¿La evolución
de las formas del
trabajo y de la pro-
piedad moderna
no han destruido
casi todo rastro de
vida recíproca, de
relación plena de
sentidlo?"

que la educación actual necesita ser reorientada a hallar el sentido de la existencia planetaria:

Entre tantas excelencias propias del concepto de cuidado, quiero hacer hincapié en dos que interesan a la nueva educación: la integración del globo terrestre en nuestro imaginario cotidiano y el encantamiento por el misterio de la existencia. Cuando contemplamos el planeta Tierra desde el espacio exterior, surge en nosotros un sentimiento de reverencia al ver nuestra única Casa Común. Somos inseparables de la Tierra, formamos un todo con ella. Sentimos que debemos amarla y cuidarla para que nos pueda ofrecer todo lo que necesitamos para seguir viviendo.

Al mismo tiempo, la teoría de Buber hace una distinción entre "individuo y persona", ya que el primero vive en el mundo mediante una vinculación con el ello, a diferencia de la persona que se reafrma en la relación con los otros seres (animados e inanimados), es decir el "Tú", mediante el diálogo, la expresión, la manifestación recíproca y horizontal entre seres.

Sin duda, este profesor judeocristiano de principios de siglo XX enaltece la comunicación entre los hombres, y de éstos con la naturaleza, mediada por el lenguaje, pues en ella está el sentido de la existencia:

El mundo de relación se construye en tres esferas: la primera es nuestra vida con la naturaleza, en ella la relación llega hasta el umbral del lenguaje. En la segunda esfera, la de nuestra vida con los hombres, la relación adquiere la forma del lenguaje; la tercera esfera es nuestra vida con las formas inteligibles; la relación se produce en ella sin lenguaje, pero engendra un lenguaje (79).

Por tanto, el ser humano es el que posee la capacidad de "elegir y ser elegido", es decir, tiene la posibilidad de autoafrmar el "Yo" al entrar en diálogo con un "Tú".

De esta forma, Buber manifesta en su flosofía la expresión máxima del amor y la comunicación, la cual proviene de la relación de Dios con el hombre, el hombre con la naturaleza y el hombre en relación con los otros hombres.

En consecuencia, una pedagogía ambiental sólo puede ser práctica dialógica, cuando a partir del lenguaje y la comunicación se reconoce al "Yo", y al otro como un "Tú", partes imprescindibles del ser.

Pero corresponde al pedagogo francés Celestin Freinet proponer el concepto de comunicación a partir de la interacción, diálogo, comprensión y construcción del mundo desde los educandos. Este maestro de origen francés frustrado por sus quebrantos de salud y desanimado porque las propuestas pedagógicas de los grandes pensadores no eran posibles para su escuela de escasos recursos ubicada en los Alpes marítimos llamado Bar-sur-Loup, ingenió cómo superar estos obstáculos, y propuso como eje "la imprenta", instrumento de escritura que convirtió en un auténtico medio de comunicación, al crear junto con sus educandos "el periódico escolar". De esta forma, este medio convirtió rápidamente la clase en un espacio pedagógico de expresión y comunicación como lo expone Elise Freinet compañera del maestro provenzal (1975): 
Partimos de ideas muy simples, con herramientas muy rudimentarias: una imprenta que concedía un lugar de honor a un texto libre que, era ante todo, texto libre; correspondencia que, en seguida, tomó una nueva forma, al ser aprobada por todos; fcheros autocorrectivos fabricados por nosotros mismos, dibujos libres en simples pedazos de papel; grabado sobre cartón húmedo (9).

En este sentido para Celestin Freinet (1974) la expresión libre se constituía en la esencia del proceso pedagógico:

El texto libre, que es la expresión natural, es la base de la vida infantil en su medio normal; la observación y la experimentación como fundamentos indispensables para el aprendizaje de las ciencias, del cálculo, la historia y la geografía; el dibujo, la pintura, y la música libres, expresión complementaria en el aspecto afectivo y artístico de las posibilidades latentes en el niño como vías de acceso a una cultura, no solamente escolar, sino social y humana (10).

De este modo, los educandos encontraron en la máquina de escribir incorporada al aula por el maestro de Provenza, la oportunidad de crear, escribir, proponer, dialogar, debatir, participar, compartir, en otras palabras, transformar la acción pedagógica en una práctica comunicadora y social. En términos de Kaplún (1992):

Obviamente ahora sí todos los niños estaban activos y ocupados: unos redactan, otros componen o imprimen. Pero fue algo más que una solución al problema del quehacer. Aquel medio de comunicación cambió toda la dinámica de la enseñanza-aprendizaje. Los pequeños periodistas aprendían realmente a redactar para expresar sus ideas; a estudiar e investigar de verdad, porque ahora tenían una motivación y un estímulo para hacerlo: ese conocimiento que producían ya no era para cumplir una obligación (...) sino para publicarlo, comunicarlo, compartirlo con los compañeros, con los padres, con los vecinos del pueblo (24-25).

Así, el uso pedagógico de la imprenta permitió todo un despliegue de la comunicación humana y mediática a inicios del siglo XX. Por ello, Celestin Freinet (1974) enfatizó:

Sí la redacción no tiene otro objetivo más que las correcciones y la nota que le adjudicáis, si estáis convencidos de que el niño no puede crear ni pensar por sí mismo y sólo puede alimentarse de vuestra riqueza, obtendréis de él "deberes", pero nunca "obras" capaces de poner de manifesto una personalidad (20).

Para Prieto (1999) "Freinet quería que los educandos compusieran sus propios textos en los que pudieran expresar su visión de la vida, su familia, de su contexto, de sus vivencias (...)." (77).

Esto es signifcativo para una educomunicación ambiental que pretenda la participación democrática de todos los humanos en la salvación del planeta, al suscitar cuestionamientos, metodologías y propuestas alternativas, como lo hizo Freinet. En este aspecto coincide Novo (2006) respecto a las metodologías para una educación ambiental:

La educación ambiental desde y sobre la complejidad plantea a los profesores la posibilidad de convertir los espacios educativos en ámbitos en los que se formulen "preguntas legítimas", es decir, pregun- 
tas cuya respuesta no está construida, y en relación con las cuales es posible que cada persona elija las informaciones y los métodos interpretativos, de manera que los resultados no sean previsibles, resulten abiertos e incluso puedan considerarse como el principio de nuevos interrogantes (413).

Pero esta experiencia pedagógica educomunicacional del maestro provenzal va más allá de los límites de aquel remoto pueblo, pues "el periódico escolar" producido por los educandos trasciende las fronteras para comunicar sus experiencias con otros niños y jóvenes en iguales condiciones que se interesaron por el periódico y por comenzar a producir sus propio medio de comunicación, convirtiéndose esta vivencia en un fujo comunicante. Expresa a este respecto Kaplún (1992):

La colección del periódico escolar se fue haciendo memoria colectiva del grupo, registro de su proceso de descubrimiento y de sus avances en la producción de conocimiento. De adquisición individual, el saber pasó a transformarse en construcción colectiva, en producto social (...) y los periódicos escolares empiezan a multiplicarse en distintas escuelas públicas de Francia, todas ellas pobres y relegadas (25).

Ahora bien, esta pedagogía de la comunicación promovida por el maestro Provenzal, también se constituye en una pedagogía ambientalista al promover la expresión libre de los educandos a partir de su entorno, de su rol social, pues habla de sus labores diarias en el campo, de sus relaciones con el medio que los rodea, en este sentido Elise Freinet manifesta (1975):

La imprenta no fue tan sólo un medio para que el niño actuase en el sentido físico e intelectual, por oposición a la inmovilidad impuesta por la escuela tradicional; tampoco fue un medio para reactivar el interés escolar del niño hacia tal o cual asignatura. Fue mucho más que esto: abrió ante Freinet la personalidad psicológica y humana del niño en su devenir y en relación estrecha con su ambiente (38).

Entre tanto, para Kaplún (1992) esta experiencia de Freinet se conforma en una "caja de resonancia" donde el educando se expresa a partir de su sentir y del tipo de relaciones que establece con el medio que lo rodea:

Hay que informarles bien, explicarles cómo vivimos, qué comemos, cómo trabajamos el campo, qué cosechamos, qué fabricamos, qué árboles hay, qué tipo de animales, cómo nos divertimos, qué festas y costumbres tenemos. Casi sin que el maestro deba intervenir, se organizan, se reparten tareas y se lanzan a la calle a ampliar datos, a entrevistar a los granjeros y a los artesanos; a exhumar documentos en el archivo municipal; a trazar planos del pueblo y mapas de los campos y montes circundantes; a conversar con los abuelos para rescatar y reconstruir la historia y las tradiciones del lugar. (26). 
Este reconocimiento de sí mismo, del otro y del contexto tiene un sentido muy relevante para signifcar "lo ambiental":

Cuando hablamos de "lo ambiental" o de "la dimensión política de lo ambiental", nos estamos refriendo a nosotros mismos, a nuestras propias vidas como individuos y como comunidad, a nuestras propias condiciones de existencia. Podríamos afrmar como Berman que "nosotros somos nuestro ambiente" (Ministerio de Ambiente, Vivienda y Desarrollo Territorial, 33).

Así, la experiencia comunicacional de Freinet se constituiría, a la postre, en un modelo seguido por todos aquellos maestros que buscan hacer ruptura a los métodos tradicionales para introducir nuevas formas de ver, percibir, sentir y construir, no sólo un conocimiento especializado sino un conocimiento humano, vivencial, natural y ambiental.

\section{Conclusión}

Comenio, Rousseau, Pestalozzi, Buber y Freinet, se erigieron en los pedagogos del pensamiento Occidental moderno al refexionar la naturaleza humana y social desde el niño, el hombre, el maestro, la familia, la escuela, los métodos, entre otros. Revisión que permitió abordar las dimensiones de la comunicación humana, así como de la relación del hombre con la naturaleza, a fín de develar posibles cimientos para un diseño de educomunicación ambiental. Por tanto, pretende ser un aporte signifcativo, en tiempos en que la furia de la tierra cobra a la especie humana toda su indiferencia, a la vez que en la sociedad globalizada urge la pregunta por el sentido de lo humano.

\section{Referencias bibliográfcas}

Böhm, W y Schiefelbein, S. (2004). Repensar la educación. Bogotá: Pontifcia Universidad Javeriana.
Boff, L. (2002). Ética de lo humano compasión por la tierra. Buenos aires: Trotta.

Boff, L. (2009). Respeto a todo ser, a la madre tierra. Disponible en: http://www.servicioskoinonia. org/boff/articulo.php?num =333

Boff, L. (2011). El planeta va a seguir con febre. Disponible en:http://www.servicioskoinonia.org/ boff/articulo.php?num $=416$

Boff, L. (2011). Educar para celebrar la vida y la tierra. Disponible en: http://www.servicioskoinonia. org/boff/articulo.php?num $=451$

Buber, M. (1994). Yo y Tú. Buenos aires: Nueva Visión

Comenio, J. (2003). Didáctica Magna. México: Porrúa.

Chateau, J. (2005). Los grandes pedagogos. México: Fondo de Cultura económica

Fernández-Rañada, A. (2003). Los muchos rostros de la ciencia. México: Fondo de Cultura Económica.

Ferres, J. (2008). La Educación como industria del deseo. Un nuevo estilo educomunicativo. Barcelona: Gedisa

Freinet, C. (1974). El diario escolar. Barcelona: Laia

Freinet, E. (1975). Nacimiento de una pedagogía popular. (Historia de la Escuela Moderna) Barcelona: Laia.

Joly, M. (2009). Análisis de la imagen. Buenos aires: La Marca editora.

Jonas, H. (1975). El principio de responsabilidad: Ensayo de una ética para la civilización tecnológica. Barcelona: Herder.

Kaplún, M. (1987). El comunicador popular. Buenos aires: Lumen humanitas

Kaplún, M. (1992). A la educación por la comunicación. Santiago de Chile: UNESCO/ORELAC

Leff, E. (2006). Aventuras de la epistemología ambiental. México: Siglo XXI.

Lugari, P. (2009). Por la piel de la tierra. En un proyecto Casa Editorial El Tiempo-Fundación Ética mundial. Fascículo 35. Cali: El Tiempo. (287)

Ministerio de Ambiente, Vivienda y Desarrollo social (2006). Brújula, bastón y lámpara para trasegar los caminos de la Educación Ambiental. Bogotá. 
Novo, M (2006). El desarrollo sostenible su dimensión ambiental y educativa.Pearson Educación.

Pautassi, J. (1999). Ética ambientalista. En Revista Universidad de La Salle. (28), 109-124.

Prieto, D. (1996). El juego pedagógico. En La pasión por el discurso. Medellín: Universidad Pontifcia Bolivariana.

Prieto, D. (1999). La comunicación en la educación. Buenos aires: Ciccus.

Rousseau, J.J. (2005). Emilio o de la educación. Bogotá: editorial Unión Limitada.

Wolton, D. (2006). Salvemos la comunicación. Barcelona: Gedisa. 
